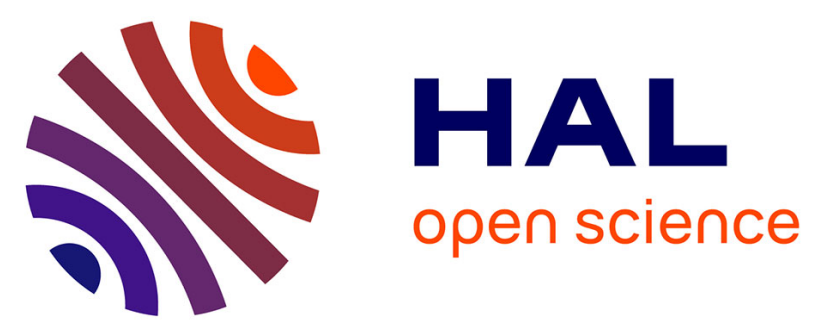

\title{
Synchronous Active Proportional Resonant-Based Control Technique for High Penetration of Distributed Generation Units into Power Grids
}

Majid Mehrasa, Radu Godina, Edris Pouresmaeil, Ionel Vechiu, Rubén L Rodríguez, João Catalão

\section{To cite this version:}

Majid Mehrasa, Radu Godina, Edris Pouresmaeil, Ionel Vechiu, Rubén L Rodríguez, et al.. Synchronous Active Proportional Resonant-Based Control Technique for High Penetration of Distributed Generation Units into Power Grids. IEEE International Conference on Innovative Smart Grid Technologies (ISGT Europe 2017), Sep 2017, Turin, Italy. hal-01657635

\section{HAL Id: hal-01657635 \\ https://hal.science/hal-01657635}

Submitted on 6 Dec 2017

HAL is a multi-disciplinary open access archive for the deposit and dissemination of scientific research documents, whether they are published or not. The documents may come from teaching and research institutions in France or abroad, or from public or private research centers.
L'archive ouverte pluridisciplinaire HAL, est destinée au dépôt et à la diffusion de documents scientifiques de niveau recherche, publiés ou non, émanant des établissements d'enseignement et de recherche français ou étrangers, des laboratoires publics ou privés. 


\section{Synchronous Active Proportional Resonant-Based Control Technique for High Penetration of Distributed Generation Units into Power Grids}

\author{
Majid Mehrasa and \\ Radu Godina \\ C-MAST/UBI, \\ Portugal
}

\author{
Edris Pouresmaeil \\ ESTIA Institute of Technology, \\ France, and INESC-ID/ \\ IST-UL, Portugal
}

\author{
Ionel Vechiu and \\ Rubén L. Rodríguez \\ ESTIA Institute of \\ Technology, France
}

\author{
João P. S. Catalão \\ INESC TEC and FEUP, \\ C-MAST/UBI, and \\ INESC-ID/IST-UL, Portugal
}

\begin{abstract}
This paper deals with a synchronous active proportional resonant-based (SAPR) control technique for interfaced converters, enhancing the stable operation of the power grid under high penetration of distributed generation sources. By considering the grid specifications and load currents, both $d$ and $q$ axis of converter currents are obtained in terms of active and reactive power and also angular speed using small-signal linearization method. Then, swing equation is analyzed in detail to achieve the reference current components in the current control loop of the interfaced converter. By using the obtained swing equation and a non-ideal proportional resonant (PR) controller, a new control technique is proposed, which introduces the behavior of synchronous power generators based on power electronic converters in distributed generation (DG) technology. The effectiveness of the proposed control technique is verified through stringent simulation studies in MATLAB/SIMULINK.
\end{abstract}

Index Terms-Distributed generation (DG), synchronous active PR-based (SAPR), synchronous power generator.

\section{INTRODUCTION}

The integration of distributed generation (DG) units based on renewable energy sources, such as wind and solar, into the power grid has been increasing in recent years. The potential of DG technology is high as renewable energy sources can meet the energy demand safely and soundly. In addition, these sources can provide sustainable energy services, based on available local and small-scale power generation [1]-[2].

However, high penetration of DG units, which are based on power electronic converters for the connection of renewable energies to the power grid, leads to several stability problems in voltage and frequency associated with grid operation [3]-[4]. The lack of inertia in power electronic-based generators and their transient behavior increase the negative impacts on the grid operation and hinders their integration into the power grid, just the opposite of what happens with synchronous power generators.

Thus, such power generators should be accompanied with some specific functionalities to make them compatible with the behavior of synchronous power grids and thus effectively achieving their high penetration [5].

Several researches have been done for integration of largescale DG sources into the power grid [6]-[7]. In [8], a mathematical model is proposed based on PV generation system and a $\mathrm{H} \infty$ control theory is designed as voltage tracking controller of the PV generation systems with capability of flexible connection into the power grid.

In [9], with the knowledge of different loads and wind conditions, a new unit scheduling criteria is proposed to integrate the system equivalent speed droop along with the $\mathrm{M}$ factor. Also, in [9] the system reliability is considered, specifying the maximum allowable power loss and the required size of the operating reserve.

Considering the multiple operation periods and security limitations, [10] presents a comprehensive model predictive control (MPC) scheme for a loop power flow controller-based (i.e., LPC-based) active distribution network (ADN) to show stable operation in presence of variations in output of distributed generations. In the next step, also an improved double description approximation method is designed for easily linearizing the non-convexity security limitations of LPC-ADN.

For solving the problems of the voltage rise due to the peak PV generation and also the voltage drop due to the peak load, a coordinated control strategy is proposed in [11] to set the charge/discharge of battery storage systems by combining the local droop based control method and a distributed control scheme. 
In order to assess the effect of random wind power generation on the small signal stability of power system, a systematic nonlinear analytical probabilistic method is proposed in [12], which is able to make linear approximation between the wind generation and the damping of a dominant dynamic mode in high penetration of wind generation.

In this paper, a synchronous active proportional resonantbased (SAPR) control technique is presented to guarantee the stable operation of the power grid under high penetration of distributed generation sources. After introduction, the rest of the paper is organized as following. Proposing a dynamic equation consisting of grid specifications and load currents in section II. In section III, the proposed control technique is designed by using Small signal linearization. The next subsections are related to designing controller for $\mathrm{d}$ and $\mathrm{q}$ axis. Final part of section III is contained analyzing swing equation and PR controller. Result and discussion is placed in next section. Conclusion is stated in final section.

\section{THE Proposed MODEL}

General schematic diagram of the proposed model is shown in Fig. 1, which is consisted of energy sources, dc voltage link and controllable dc-ac power converter.

Energy sources are converted to the dc power and then a dc-ac interfaced converter is used for transforming this dc power to the ac grid, as illustrated in Fig. 1.

Based on Fig. 1, the dynamic equation of power grid can be achieved in d-q reference frame as,

$$
\begin{aligned}
& L_{g} \frac{d i_{g d}}{d t}+R_{g} i_{g d}-\omega L_{g} i_{g q}=v_{g d}-v_{d} \\
& L_{g} \frac{d i_{g q}}{d t}+R_{g} i_{g q}+\omega L_{g} i_{g d}=v_{g q}-v_{q}
\end{aligned}
$$

where, $i_{g d q}, v_{g d q}$ and $v_{d q}$ are grid currents, grid voltages and voltages of point of common coupling (PCC) in $\mathrm{d}$ and $\mathrm{q}$ reference frame, respectively. Also, $L_{g}$ and $R_{g}$ are the grid inductance and resistance, respectively.

By considering the load, grid and converter currents in Fig. 1 , (3) can be written as,

$$
i_{l d q}=i_{g d q}+i_{d q}
$$

By substituting (3) in (1) and (2), the dynamic equations based on grid specifications and load currents can be obtained.

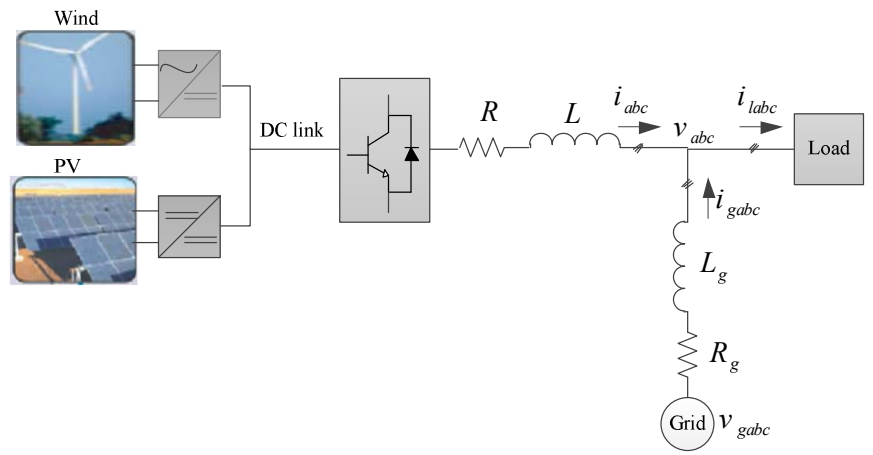

Fig. 1. General schematic diagram of the proposed model.

$$
\begin{aligned}
& L_{g} \frac{d i_{d}}{d t}+R_{g} i_{d}-\omega L_{g} i_{q}+v_{g d}-v_{d}=v_{1}\left(i_{l d}, i_{l q}\right) \\
& L_{g} \frac{d i_{q}}{d t}+R_{g} i_{q}+\omega L_{g} i_{d}+v_{g q}-v_{q}=v_{2}\left(i_{l d}, i_{l q}\right)
\end{aligned}
$$

where, $i_{d q}$ are d-q components of converter currents and $\omega$ is grid frequency angular, respectively. Also, $v_{1}\left(i_{l d}, i_{l q}\right)$ and $v_{2}\left(i_{l d}, i_{l q}\right)$ are voltages associated with the load currents and grid specifications that can be written with neglecting partial variations as,

$v_{1}\left(i_{l d}, i_{l q}\right)=R_{g} i_{l d}-\omega L_{g} i_{l q}$

$$
v_{2}\left(i_{l d}, i_{l q}\right)=R_{g} i_{l q}+\omega L_{g} i_{l d}
$$

\section{The PRoposed CONTROL TECHNIQUe}

Equation (4) which is based on the grid specifications, load currents and converter currents, are used to design two $\mathrm{d}$ and $\mathrm{q}$ axis of the proposed control technique.

Small signal linearization is main approach for completing this section that is discussed more in following subsection.

\section{A. d-Axis of the Proposed Control Technique}

Applying small signal linearization to equation (4), the following linearized equations can be achieved as,

$$
\begin{aligned}
& \left(L_{g} s+R_{g}\right) \Delta i_{d}-L_{g} i_{q}^{*} \Delta \omega-\omega^{*} L_{g} \Delta i_{q}+\Delta v_{g d}-\Delta v_{d} \\
& =\Delta v_{1}\left(i_{l d}, i_{l q}\right)
\end{aligned}
$$

$$
\begin{aligned}
& \left(L_{g} s+R_{g}\right) \Delta i_{q}+L_{g} i_{d}^{*} \Delta \omega+\omega^{*} L_{g} \Delta i_{d}+\Delta v_{g q}-\Delta v_{q} \\
& =\Delta v_{2}\left(i_{l d}, i_{l q}\right)
\end{aligned}
$$




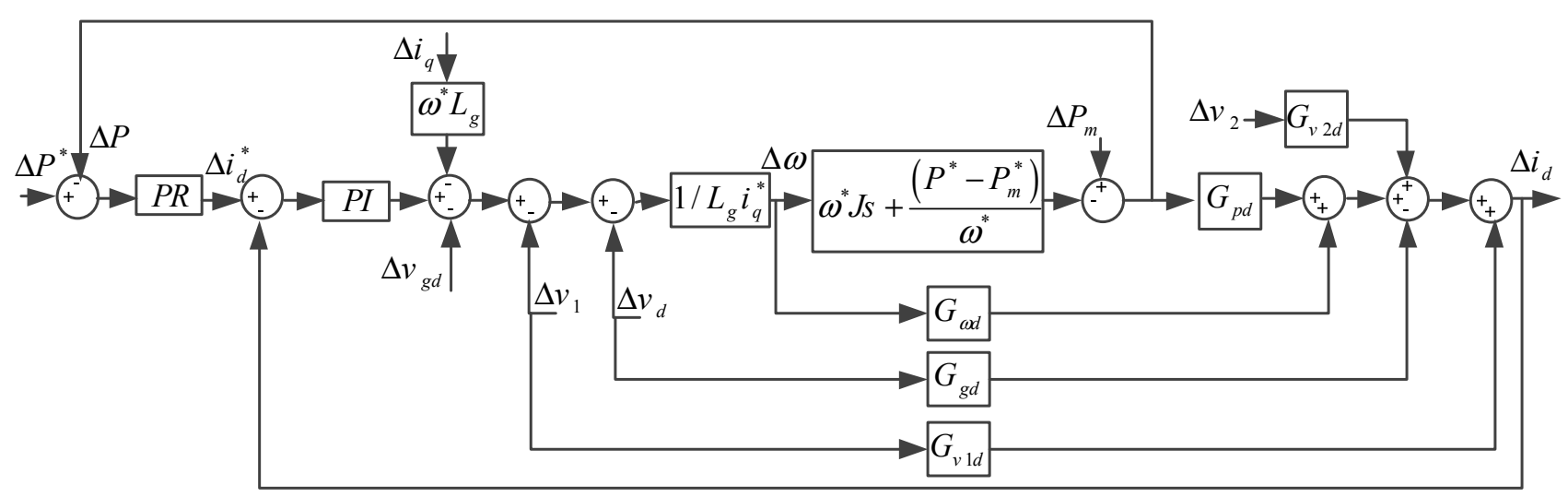

Fig. 2. The overall structure of d-axis of the proposed control technique.

For the interfaced converter, the relation between active power and d component of converter current can be expressed as $i_{d}=P / v_{d}$ and its small signal linearization term can be written as,

$\Delta i_{d}=\frac{\Delta P v_{d}^{*}-\Delta v_{d} P^{*}}{v_{d}^{* 2}}$

Using $\Delta v_{d}$ and $\Delta i_{q}$ driven from (6) and (7) and substituting them into (8), the perturbation term of d-axis converter current can be achieved after performing some simplifications as,

$$
\begin{aligned}
& \Delta i_{d}=G_{p d} \Delta P+G_{\omega d} \Delta \omega+G_{v 2 d} \Delta v_{2}\left(i_{l d}, i_{l q}\right) \\
& -G_{g d} \Delta v_{g d}+G_{v 1 d} \Delta v_{1}\left(i_{l d}, i_{l q}\right)
\end{aligned}
$$

By defining $\Delta \Psi_{d}$ as below,

$$
\Delta \Psi_{d}=\left(v_{d}^{* 2}+P^{*}\left(L_{g} s+R_{g}\right)+\frac{\omega^{* 2} P^{*} L_{g}^{2}}{\left(L_{g} s+R_{g}\right)}\right)
$$

The function transfer gains given in (9), can be stated as following,

$$
\begin{aligned}
G_{p d} & =\frac{v_{d}^{*}}{\Delta \Psi_{d}}, G_{\omega d}=\frac{\left(L_{g} i_{q}^{*} P^{*}-L_{g}^{2} i_{d}^{*} \omega^{*} P^{*}\right)}{\Delta \Psi_{d}} \\
G_{v 1 d} & =\frac{P^{*} \Delta v_{1}\left(i_{l d}, i_{l q}\right)}{\Delta \Psi_{d}}, G_{v 2 d}=\frac{\omega^{*} P^{*} L_{g}}{\Delta \Psi_{d}\left(L_{g} s+R_{g}\right)} \\
G_{g d} & =\frac{P^{*}}{\Delta \Psi_{d}}
\end{aligned}
$$

By using (6) and (9), the main part of d-axis of the proposed control technique can be achieved that is drawn in Fig. 2.

\section{B. q-Axis of the Proposed Control Technique}

Equation (7) is employed in this section. For a three phase dc-ac converter, relationship between active and reactive power can be written as (12),

$P i_{q}=-Q i_{d}$

Applying small signal linearization to (12), (13) can be driven as,

$\Delta P i_{q}^{*}+\Delta Q i_{d}^{*}=-P^{*} \Delta i_{q}-Q^{*} \Delta i_{d}$

By obtaining $\Delta i_{d}$ from (6) and substituting into (13), (14) can be obtained as,

$$
\begin{aligned}
& \Delta P i_{q}^{*}+\Delta Q i_{d}^{*}=\left(-P^{*}-Q^{*} \frac{\omega^{*} L_{g}}{\left(L_{g} s+R_{g}\right)}\right) \Delta i_{q}-\frac{Q^{*} L_{g} i_{q}^{*} \Delta \omega}{\left(L_{g} s+R_{g}\right)} \\
& +\frac{Q^{*} \Delta v_{g d}}{\left(L_{g} s+R_{g}\right)}-\frac{Q^{*} \Delta v_{d}}{\left(L_{g} s+R_{g}\right)}-\frac{Q^{*} \Delta v_{1}\left(i_{l d}, i_{l q}\right)}{\left(L_{g} s+R_{g}\right)}
\end{aligned}
$$

Consequently, the perturbation term of q-axis converter current can be calculated as,

$$
\begin{aligned}
& \Delta i_{q}=G_{p q} \Delta P+G_{q q} \Delta Q+G_{\omega q} \Delta \omega+G_{v 1 q} \Delta v_{1}\left(i_{l d}, i_{l q}\right) \\
& -G_{g q} \Delta v_{g d}+G_{d q} \Delta v_{d}
\end{aligned}
$$

By assuming $\Delta \Psi_{q}$ as (16),

$\Delta \Psi_{q}=\left(-P^{*}-Q^{*} \frac{\omega^{*} L_{g}}{\left(L_{g} S+R_{g}\right)}\right)$ 
The gains of transfer function (15) can be achieved as,

$$
\begin{aligned}
G_{p q} & =\frac{i_{q}^{*}}{\Delta \Psi_{q}}, G_{q q}=\frac{i_{d}^{*}}{\Delta \Psi_{q}}, G_{\omega q}=\frac{Q^{*} L_{g} i_{q}^{*}}{\left(L_{g} s+R_{g}\right) \Delta \Psi_{q}} \\
G_{g q} & =\frac{Q^{*}}{\left(L_{g} s+R_{g}\right) \Delta \Psi_{q}}, G_{d q}=\frac{Q^{*}}{\left(L_{g} s+R_{g}\right) \Delta \Psi_{q}} \\
G_{v 1 q} & =\frac{Q^{*}}{\left(L_{g} s+R_{g}\right) \Delta \Psi_{q}}
\end{aligned}
$$

The proposed control technique is consisted of two axis in which the main part of its $\mathrm{q}$ axis component can be driven by using the equations (7) and (15) as illustrated in Fig. 3.

\section{Analyzing Swing Equation and PR controller}

Both swing equation and non-ideal PR controller are used in this section to add behavior and characteristic of synchronous power generators to the proposed control technique.

The mechanical and electrical parts of a synchronous power generators can be linked based on the following equation as,

$\frac{1}{2} J \frac{d\left(\omega^{2}\right)}{d t}=P_{m}-P$

where, $J, P_{m}$ and $P$ are its moment of inertia, mechanical power and electrical power of synchronous power generators, respectively. By using small signal linearization, (18) can be rewritten as,

$$
\Delta P_{m}-\Delta P=\left(\omega^{*} J_{S}+\left(P^{*}-P_{m}^{*}\right) / \omega^{*}\right)(\Delta \omega)
$$

Equation (19) is employed for achieving active power based on characteristics of synchronous power generators.
The synchronous features of the proposed control technique generate additional closed-loop controller for both $\mathrm{d}$ and $\mathrm{q}$ axis components as shown in Fig. 2 and Fig. 3 ,

A non-ideal PR controller is defined as, respectively.

$$
[P R](s)=k_{p}+\frac{2 k_{r} \omega_{c} s}{s^{2}+2 \omega_{c} s+\omega_{0}^{2}}
$$

where, $k_{p}, k_{r}, \omega_{0}$ and $\omega_{c}$ are proportional gain, resonant gain, resonant frequency and cut-off frequency, respectively. As it can be seen from Fig. 2 and Fig. 3, PR controller is responsible to approach to desired values for $\mathrm{d}$ and $\mathrm{q}$ axis of converter currents. The appropriate selection of PR gains and frequencies helps the proposed controller have more stable operation in various operating conditions.

\section{RESUlTS AND DISCUSSION}

The proposed model in Fig. 1 is engaged to synchronously supply a load of $14 \mathrm{~kW}+\mathrm{j} 10 \mathrm{kvar}$ at period of $[0,0.2] \mathrm{sec}$, by applying the proposed control technique to the interfaced converter. Then an additional load with $11 \mathrm{~kW}+\mathrm{j} 8 \mathrm{kvar}$ is connected to PCC at $[0.2,0.4] \mathrm{sec}$. the proposed model is simulated by MATLAB/SIMULINK to (18)verify the performance of the proposed control technique with the existence of load variations. Simulation parameters are given in Table I.

Fig. 4 shows three phase PCC voltages, magnitude and frequency of these voltages, respectively. As it can be seen from Fig. 4(a), the PCC voltages are stable and balanced under load variation condition. The proposed control technique performance can be seen in Fig. 4(b) and Fig. 4(c) where both voltage magnitude and frequency are kept in acceptable changes range with very small transient response.

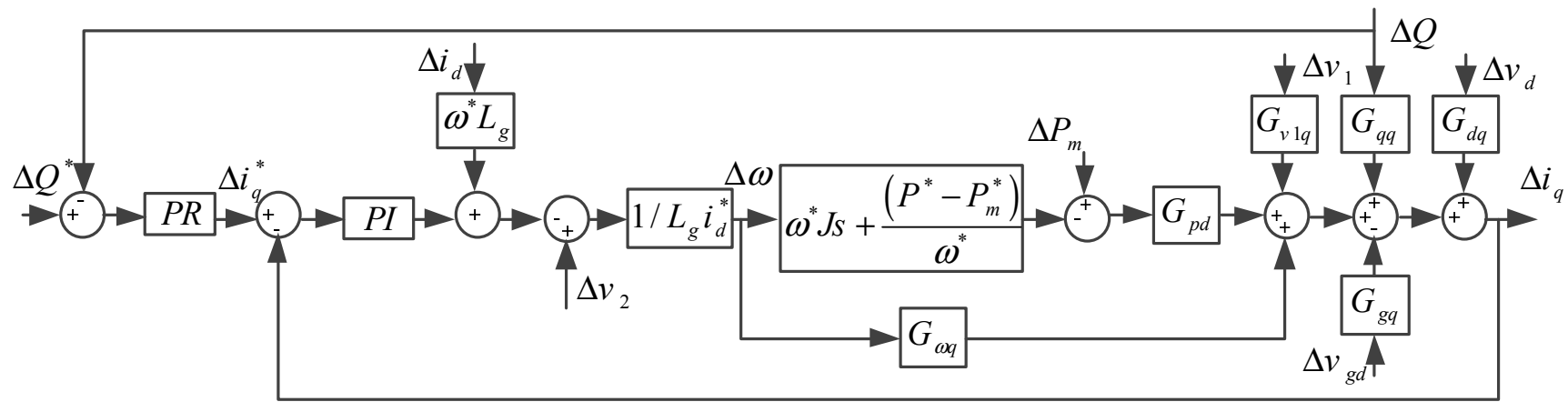

Fig. 3. The overall structure of q-axis of the proposed control technique. 


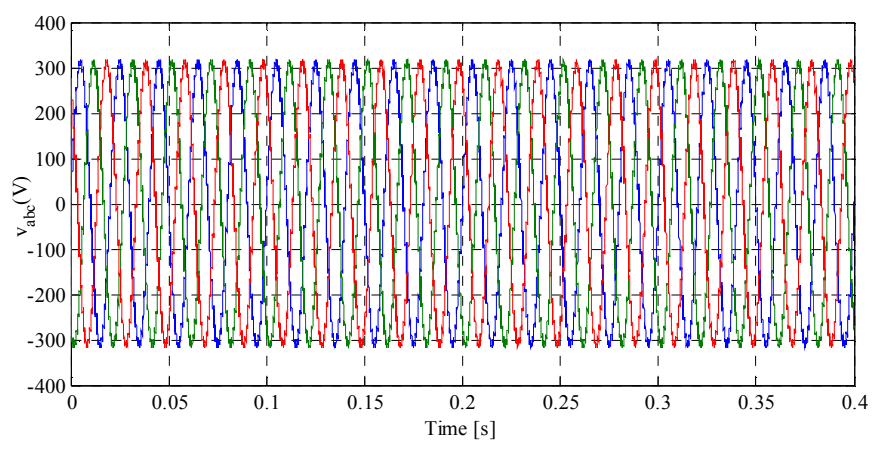

(a)

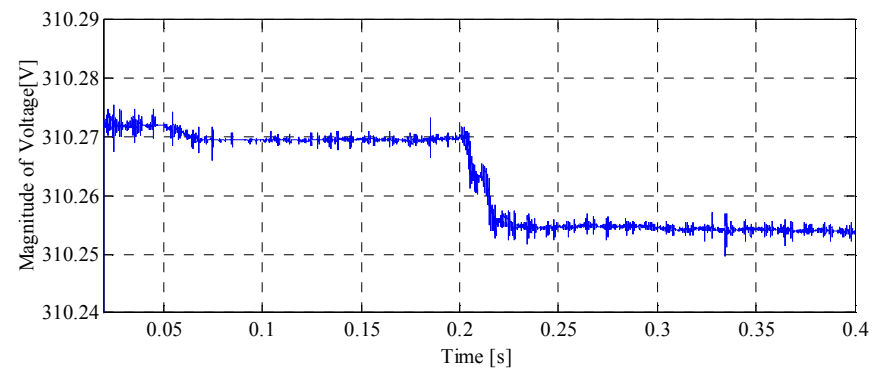

(b)

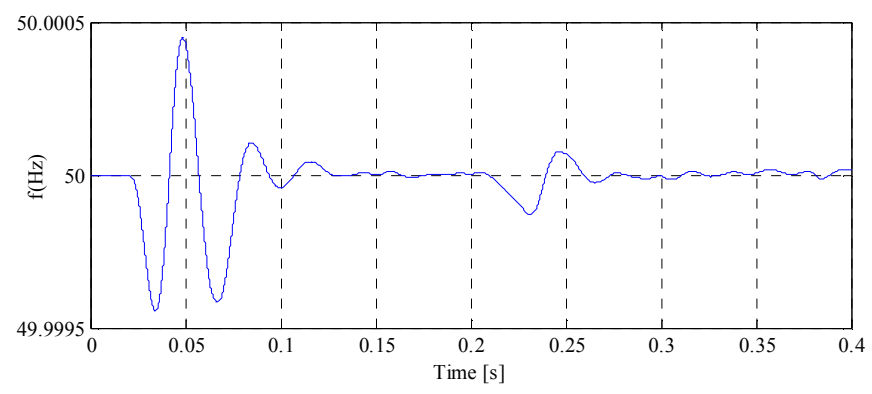

(c)

Fig. 4. (a) Three phase voltage at PCC, (b) magnitude of the voltage at PCC, and (c) Frequency of the voltage at PCC.

TABLE I

SIMULATION PARAMETERS

\begin{tabular}{|c|c|}
\hline Parameter & Value \\
\hline$d c$-link voltage $(\mathrm{vdc})$ & $850 \mathrm{~V}$ \\
\hline ac voltage & $310 \mathrm{~V}$ \\
\hline Fundamental frequency & $50 \mathrm{~Hz}$ \\
\hline Switching/Sampling frequency & $10 \mathrm{kHz}$ \\
\hline Resistance of grid & $0.1 \Omega$ \\
\hline Inductance of grid & $10 \mathrm{mH}$ \\
\hline $\mathrm{J}$ & $7.5 \mathrm{~s}$ \\
\hline$\Delta P_{m}$ & $10 \mathrm{~W}$ \\
\hline Load 1 & $14 \mathrm{~kW}+\mathrm{j} 10 \mathrm{kvar}$ \\
\hline Load 2 & $11 \mathrm{~kW}+\mathrm{j} 8 \mathrm{kvar}$ \\
\hline
\end{tabular}

Three phase currents of DG units are shown in Fig. 5. As can be seen from this figure, there is a synchronous behavior for both DG1 and DG2 currents in tracking the load current changes that verifies the operation of the proposed controller in this operating condition.

Synchronous active and reactive power sharing f DG units is illustrated in Fig. 6 and Fig. 7, respectively.

According to Fig. 6, active power sharing of DG units is executed with complete synchronous feature along with accurate tracing of desired values.

The same scenario happens for synchronous reactive power sharing of DG1 and DG2 units as depicted in Fig. 7.

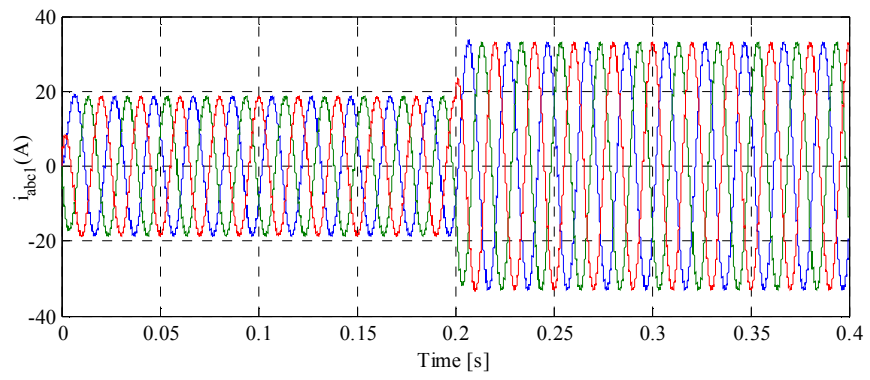

(a)

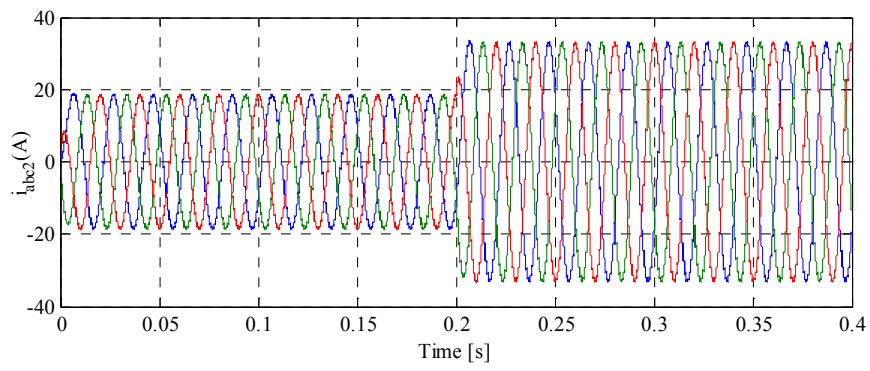

(b)

Fig. 5. Three phase currents of (a) DG1, and (b) DG2.

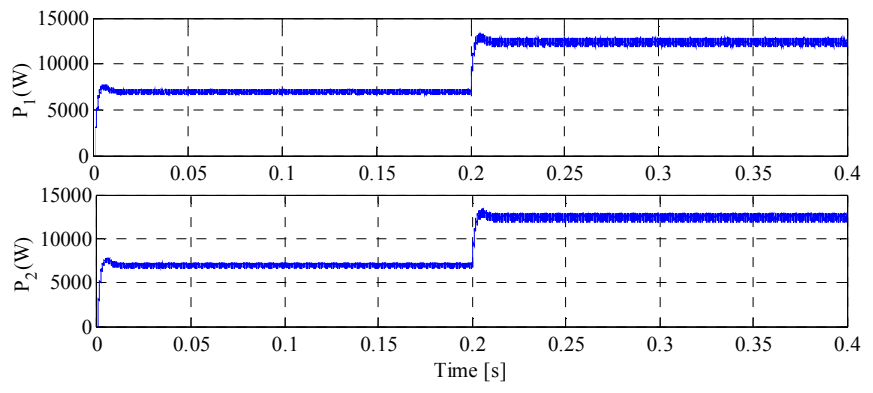

Fig. 6. Active power sharing between DG1 and DG2. 

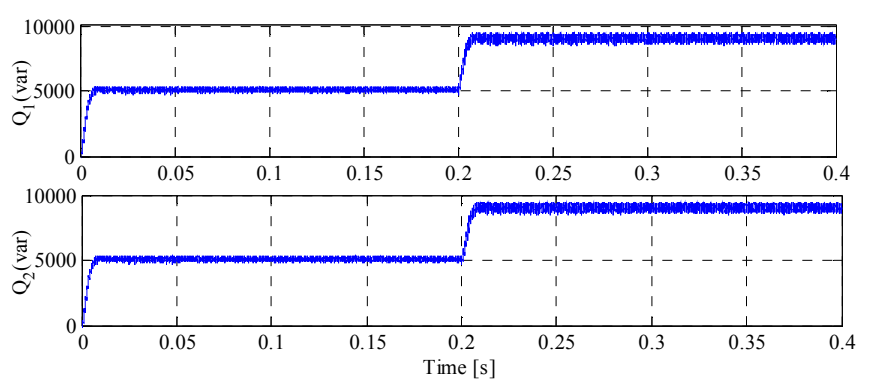

Fig. 7. Reactive power sharing between DG1 and DG2.

\section{CONCLUSION}

A SAPR control technique was presented in this paper to regulate the grid operation in stable operating mode under high penetration of DG units into the power grid. By achieving the mathematical model consisting of the grid specifications and the load currents, a small signal linearization was applied to the proposed model that leads to the calculation of the $\mathrm{d}$ and $\mathrm{q}$ current components of the interfaced converter. In order to add synchronous generators features to both $\mathrm{d}$ and $\mathrm{q}$ axis of the proposed control technique, the swing equation has been utilized. To ensure an effective performance of both $\mathrm{d}$ and $\mathrm{q}$ axis controllers, a non-ideal PR controller was used. Simulation results confirmed that the control technique can guarantee a stable operation of the power grid during the integration of large-scale distributed generation sources.

\section{ACKNOWLEDGMENTS}

This work was supported by INSUL'GRID project, France, by FEDER funds through COMPETE 2020 and by Portuguese funds through FCT, under Projects SAICT-PAC/0004/2015 POCI-01-0145-FEDER-016434, POCI-01-0145-FEDER006961, UID/EEA/50014/2013, UID/CEC/50021/2013, UID/EMS/00151/2013, and SFRH/BPD/102744/2014. Also, the research leading to these results has received funding from the EU Seventh Framework Programme FP7/2007-2013 under grant agreement no. 309048.

\section{REFERENCES}

[1] M. Mehrasa, E. Pouresmaeil, B. N. Jørgensen, J. P.S. Catalão, “A control plan for the stable operation of microgrids duringgridconnected and islanded modes," Electric Power Systems Research, vol. 129, pp. 10-22, July. 2015.

[2] M. Mehrasa, M. E. Adabi, E. Pouresmaeil, J. Adabi, "Passivitybased control technique for integration of DG resources into the power grid," International Journal of Electric Power Systems Research, vol. 58, pp. 281-290, January. 2014.

[3] M. Chamana, B. H. Chowdhury, and F. Jahanbakhsh, "Distributed Control of Voltage Regulating Devices in the Presence of High PV Penetration to Mitigate Ramp-Rate Issues," IEEE Trans. Smart Grid, DOI 10.1109/TSG.2016.2576405.

[4] X. Liang, "Emerging Power Quality Challenges Due to Integration of Renewable Energy Sources," IEEE Trans. Industry Applications, DOI 10.1109/TIA.2016.2626253.

[5] E. Pouresmaeil, M. Mehrasa, and J. P. S. Catalão, "A Multifunction Control Strategy for the Stable Operation of DG Units in Smart Grids," IEEE Trans. on Smart Grid, vol. 6, no. 2, pp. 598-607, Mar. 2015.

[6] E. Pouresmaeil, M. Funsho Akorede, D. Montesinos-Miracle, and O. Gomis-Bellmunt, "Hysteresis Current Control Technique of VSI for Compensation of Grid-connected Unbalanced Load," Electrical Engineering, vol. 96, pp. 27-35, Feb. 2014.

[7] M. Mehrasa, E. Pouresmaeil, M. Funsho Akorede, B. N. Jrgensen, and J. P. S. Catalao, "Multilevel Converter Control Approach of Active Power Filter for Harmonics Elimination in Electric Grids," Energy, vol. 84, pp. 722-731, May 2015.

[8] P. Li, X. Yu, J. Zhang, and Z. Yin, "The Hळ Control Method of Grid-Tied Photovoltaic Generation," IEEE Trans. Smart Grid, vol. 6, pp. 1670-1677, July. 2015.

[9] C-A. Chang, T-C. Lo, Y-K. Wu and B-K Chen, "Simplified Frequency Estimation for Unit Scheduling Criteria for Grids with High Wind Penetration," IEEE Trans. Industry Applications, DOI 10.1109/TIA.2017.2650984.

[10] X. Xing, J. Lin, C. Wan, Y. Song, "Model Predictive Control of LPC-looped Active Distribution Network with High Penetration of Distributed Generation," IEEE Trans. Sustainable Energy, doi.org/10.1109/TSTE.2016.2647259.

[11] M. Zeraati, M. E. H. Golshan, and J. M. Guerrero, "Distributed Control of Battery Energy Storage Systems for Voltage Regulation in Distribution Networks with High PV Penetration," IEEE Trans. Smart Grid, DOI 10.1109/TSG.2016.2636217.

[12] Z. W. Wang, C. Shen, and F. Liu, "Probabilistic Analysis of Small Signal Stability for Power Systems With High Penetration of Wind Generation," IEEE Trans. Sustainable Energy, vol. 7, pp. 11821193, July. 2016. 